\title{
Separation and Enrichment of Alkylated Globin Chains as a Means of Improving the Sensitivity of Hemoglobin Adduct Measurements
}

\author{
Emma Bergmark, ${ }^{\mathrm{a}, \mathrm{t}}$ Makonnen Belew ${ }^{\mathrm{b}}$ and Siv Osterman-Golkar ${ }^{\mathrm{a}}$
}

${ }^{a}$ Department of Radiobiology, Stockholm University, S-10691 Stockholm, Sweden and ${ }^{\mathrm{b}}$ Institute of Biochemistry, Uppsala University, Biomedical Center, S-75123 Uppsala, Sweden

\begin{abstract}
Bergmark, E., Belew, M. and Osterman-Golkar, S., 1990. Separation and Enrichment of Alkylated Globin Chains as a Means of Improving the Sensitivity of Hemoglobin Adduct Measurements. - Acta Chem. Scand. 44: 630-635.

Measurement of adducts of hemoglobin is a reliable and quantitative method for monitoring exposure to genotoxic chemicals. To make the approach applicable to the low levels of adducts originating from exposure to chemicals in the environment, increased sensitivity of the analytical procedures is required. The method presented here is based on quantitative determination of low levels of adducts after purification and enrichment of chemically modified (adducted) globin chains on CM-Sepharose CL-6B. In the developmental work, human globin was used after alkylation by radiolabelled ethylene oxide, styrene oxide or $N$-ethyl- $N$-nitrosourea. Ethylene oxide reacts mainly with the amino terminal valine and nitrogens in the imidazole ring of histidine, while $N$-ethyl- $N$-nitrosourea has a particularly high reactivity towards free carboxy groups of acidic amino acids. Globin chains with adducts to the carboxy groups were especially easy to separate from the non-modified chains. Ethyl adducts to carboxy groups in hemoglobin were shown to be sufficiently stable in vivo to be used for dose monitoring.
\end{abstract}

Most ultimate cancer initiators and mutagens are electrophilic reagents that react with nucleophilic atoms in cellular proteins as well as with the supposed target molecule, i.e. DNA. ${ }^{1}$ Hemoglobin $(\mathrm{Hb})$ is generally used as a monitor of ultimate carcinogens because of its ready availability and its relatively long life span which permits the determination of the effects of cumulative doses. ${ }^{2}$ Due to the correlation between the rates of formation of DNA adducts and protein adducts, the demonstration of $\mathrm{Hb}$ adducts is a relevant measure of the formation of the corresponding DNA adducts. ${ }^{3,4}$ Moreover, since no dose-response threshold can be defined for genotoxic action, the demonstration of $\mathrm{Hb}$ adducts could be taken as an indication of potential cancer risk. Likewise, the levels of these adducts could serve as an estimate of the level of adducts to DNA and thereby the magnitude of the risk. ${ }^{5,6}$

The measurement of $\mathrm{Hb}$ adducts has been used for monitoring known environmental factors such as occupational exposures to ethylene oxide ${ }^{7,8}$ and propylene oxide, ${ }^{9}$ tobacco smoking ${ }^{10}$ and the abuse of alcohol. ${ }^{11}$ However, improved sensitivity of the analytical procedures is mandatory in order to apply this method for the quantitative determination of the very low levels of adducts originating from exposure to chemicals in the environment and to allow identification of a priori unknown adducts.

\footnotetext{
${ }^{*}$ To whom correspondence should be addressed.
}

The exposure of proteins to reactive chemicals could result in the formation of adducts to the nucleophilic sites of some amino acids leading to a marked change in the total charge of the modified proteins. We have exploited such differences in developing an effective separation procedure, based on ion-exchange chromatography on CM-Sepharose CL-6B, to purify the chemically modified globin chains from the native ones. This method was developed as a modification of the original procedure presented by Clegg et al. ${ }^{12}$ The general applicability of this adopted separation procedure will be illustrated using human globin chains after alkylation in vitro with $\left[{ }^{14} \mathrm{C}\right]$ ethylene oxide $\left(s=0.96^{13}\right), \quad N-\left[{ }^{14} \mathrm{C}\right]$ ethyl- $N$-nitrosourea $\left(s=0.26^{14}\right)$ or $\left[{ }^{3} \mathrm{H}\right]$ styrene oxide $\left(s=0.81^{15}\right)$. These compounds show different selectivities in nucleophilic substitution reactions (as shown by their $s$ values) and give therefore different adduct spectra.

\section{Materials and methods}

Chemicals. $N-\left[{ }^{14} \mathrm{C}\right]$ Ethyl- $N$-nitrosourea $\left(30 \mathrm{mCi} \mathrm{mmol}^{-1}\right)$ and $\left[{ }^{3} \mathrm{H}\right]$ styrene oxide $\left(105 \mathrm{mCi} \mathrm{mmol}^{-1}\right)$ were bought from Amersham, Buckinghamshire, UK. $\left[1,2-{ }^{14} \mathrm{C}_{2}\right]$ Ethylene oxide $\left(22.5 \mathrm{mCi} \mathrm{mmol}^{-1}\right)$ was bought from New England Nuclear, Boston, MA. Pentafluorophenyl isothiocyanate (purum) and pentafluorobenzoyl chloride (puriss.) were from Fluka AG, Buchs, Switzerland. Dithiothreitol, 2,4dinitrophenylhydrazine and $S$-ethylcysteine were from 
Merck, Darmstadt, FRG. 1-Phenyl-1,2-ethanediol was from Aldrich, Wis, USA and 1-phenyl-2,3-propanediol, synthesized according to Duverger-van Bogaert et al. ${ }^{16}$ was a kind gift from Dr. Agneta Löf. $N^{\tau}$-Ethylhistidine was synthesized according to Murthy et al. ${ }^{17} \mathrm{CM}$-Sepharose CL-6B and Optiphase are products of Pharmacia-LKB Biotechnology, Uppsala, Sweden. Dowex $50 \mathrm{Wx} 4$ is from Carl Roth, GmbH, Karlsruhe, FRG, Ready Solve is from Beckman Fullerton, CA, USA, Other reagents and solvents were of analytical grade.

Animals. Female CBA mice (Eklunds, Vallentuna, Sweden), 8-10 weeks old, were used. The animals were fed a standard pellet diet without restrictions.

Globin samples. Alkylated hemoglobin samples were prepared essentially as described by Segerbäck et al. ${ }^{18}$ from hemolysates of human blood incubated in vitro with [1,2$\left.{ }^{14} \mathrm{C}\right]$ ethylene oxide, $N$-[1- $\left.1{ }^{14} \mathrm{C}\right]$ ethyl- $N$-nitrosourea, or $\left[{ }^{3} \mathrm{H}\right]$ styrene oxide (diluted to $0.2 \mathrm{mCi} \mathrm{mmol}^{-1}$ ). Globin was isolated according to Mowrer et al. ${ }^{19}$

Buffers. All buffers contain $8 \mathrm{M}$ urea and $1 \mathrm{mM}$ dithiothreitol to prevent the oxidation of cysteine residues. The $\mathrm{pH}$ was adjusted with phosphoric acid: Buffer A, $0.030 \mathrm{M}$ sodium phosphate, pH 6.7; Buffer $\mathrm{B}, 0.100 \mathrm{M}$ sodium phosphate, pH 6.7; Buffer $\mathrm{C}, 0.0175 \mathrm{M}$ sodium phosphate, $\mathrm{pH}$ 7.2; Buffer D, 0.035 M sodium phosphate, $\mathrm{pH}$ 7.2.

Column chromatography. Samples of 50-150 mg globin were dissolved in $2 \mathrm{ml}$ of starting buffer (A or C) and applied to a $26 \times 1.6 \mathrm{~cm}$ column of CM-Sepharose CL-6B. Immediately following sample application the adsorbed globin chains were eluted by a linear gradient of Buffer A to Buffer B (total gradient volume $=450 \mathrm{ml}$ ) or of Buffer C to Buffer $D$ (total gradient volume $=450 \mathrm{ml}$ ). The gradient was maintained using Pharmacia's GM-1 gradient mixer. The flow rate was maintained at about $30 \mathrm{ml}$ per $\mathrm{h}$ and fractions of $5 \mathrm{ml}$ were collected. The distribution of protein in the column effluents was determined by absorbance measurements at $280 \mathrm{~nm}$. The radioactivity in $1 \mathrm{ml}$ from each fraction was determined after addition of $3 \mathrm{ml}$ scintillation liquid (OptiPhase). The protein content in pooled fractions was determined according to Lowry et al. ${ }^{20}$

Analysis of adducts. 2-Hydroxyethyl and hydroxyphenethyl* adducts: Fractions containing $\alpha$ chains with hydroxyethyl adducts to valine were dialysed against water and lyophilized prior to further analysis. $N$-(2-Hydroxyethyl)valine was analysed by derivatization of the protein samples with pentafluorophenyl isothiocyanate according to Törnqvist et al., ${ }^{21}$ followed by extraction and radioactivity determination of the resulting hydantoin (PFPTH) deriv-

\footnotetext{
* Here used as a collective name for diastereomers of $\beta$-hydroxyphenethyl- and/or, possibly, $\alpha$-(hydroxymethyl)benzyl-valine.
}

ative. Hydroxyphenethyl adducts to $N$-terminal valine of the $\alpha$ and $\beta$ chains were analysed in the same way.

Pooled fractions containing hydroxyphenethyl adducts to carboxylic acid residues, were hydrolysed (without previous dialysis and lyophilization) by addition of $\mathrm{H}_{2} \mathrm{SO}_{4}$ to give $\mathrm{pH} 1$ followed by incubation at $80^{\circ} \mathrm{C}$ for $4 \mathrm{~h}$. 1-Phenyl-1,2ethanediol was extracted from the hydrolysates and derivatized with pentafluorobenzoyl chloride. ${ }^{16}$ The quantification was made on a Varian $3700 \mathrm{GC}$ with two capillary columns coupled together, i.e. a CP-sil $8 \mathrm{CB}, 50 \mathrm{~m}$, i.d. $0.25 \mathrm{~mm}$, (Chrompack) and SE54, $30 \mathrm{~m}$, i.d. $0.20 \mathrm{~mm}$, (Nordion) programmed at $3{ }^{\circ} \mathrm{C} \mathrm{min}{ }^{-1}$ from 100 to $280^{\circ} \mathrm{C}$, then continued isothermally at $280^{\circ} \mathrm{C}$ for $40 \mathrm{~min}$. The internal standard, $113 \mathrm{ng}$ 1-phenyl-2,3-propanediol was added to each sample before hydrolysis. The retention times for the derivatives of 1-phenyl-1,2-ethanediol and the internal standard were 59.2 and $62.0 \mathrm{~min}$, respectively.

Ethyl adducts: fractions having radioactivity and co-eluting with the main $\alpha$ and $\beta$ chains were pooled, dialysed and lyophilized followed by hydrolysis in $6 \mathrm{M} \mathrm{HCl}(1 \mathrm{mg} / 0.1 \mathrm{ml})$ under vacuum at $120^{\circ} \mathrm{C}$ for $16 \mathrm{~h}$. The samples were then evaporated to dryness, redissolved in water containing 5 $\mathrm{mg}$ of $S$-ethylcysteine as a carrier and chromatographed on a Dowex $50 \mathrm{Wx} 4$ cation exchange column $(1 \times 100 \mathrm{~cm})$. The column was eluted with $440 \mathrm{ml}$ of $1 \mathrm{M} \mathrm{HCl}$ followed by $2 \mathrm{M}$ $\mathrm{HCl}$ and fractions of $5 \mathrm{ml}$ were collected. From each fraction $3.5 \mathrm{ml}$ aliquots were mixed with $5.5 \mathrm{ml}$ of scintillation liquid (Ready Solve) and the radioactivity was determined. The fractions containing ethyl adducts to carboxy groups of acidic amino acids were dialysed and the adducts were recovered as radiolabelled ethanol after mild hydrolysis [reflux for $4 \mathrm{~h}$ in $\mathrm{H}_{2} \mathrm{SO}_{4}(10 \mu \mathrm{l} / \mathrm{ml})$ ], followed by distillation in the presence of carrier ethanol. ${ }^{22}$

Stability of ethyl esters in vivo. $N-\left[{ }^{14} \mathrm{C}\right]$ Ethyl- $N$-nitrosourea, dissolved in saline, was given to mice by intraperitoneal injection. The mice were anaesthetized, blood was collected and the mice were killed $4.5 \mathrm{~h}, 1,2,3,4,8,16,31$ and 39 days following administration of the test substance. The globin was isolated according to Mowrer et al. ${ }^{19}$ Protein samples $\left(40 \mathrm{mg}\right.$ ) were hydrolysed in $8 \mathrm{ml}$ of $\mathrm{H}_{2} \mathrm{O}, 4 \mathrm{ml}$ of carrier ethanol and $200 \mu \mathrm{l}$ of $\mathrm{H}_{2} \mathrm{SO}_{4}$ by being refluxed for $4 \mathrm{~h}$. To the hydrolysate was added 2,4-dinitrophenylhydrazine in order to remove labelled acetaldehyde, which might be bound to the proteins in the form of Schiff bases. Radiolabelled ethanol was recovered by distillation. Quantitative recovery of ethanol from ethyl esters is obtained in the hydrolysis. The final recovery of ethanol was determined through density measurements.

\section{Results}

The separation of $\left[{ }^{14} \mathrm{C}\right]$ ethylene oxide-alkylated globin at pH 6.7 is shown in Fig. 1. At this pH there is only a slight separation between the 2-hydroxyethylated chains and the normal non-alkylated chains. 


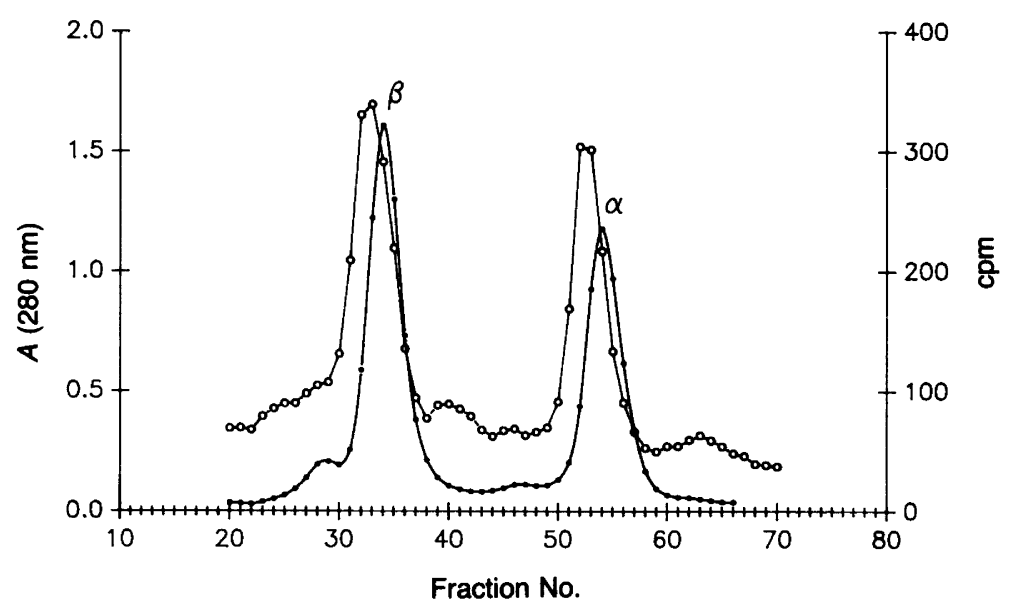

Fig. 1. Elution profile obtained after chromatography on CM-Sepharose CL-6B of 100 $\mathrm{mg}$ of globin alkylated in vitro with $\left[{ }^{14} \mathrm{C}\right]$ ethylene oxide. The column was equilibrated with Buffer $A$ and the adsorbed globin chains eluted with a linear gradient of Buffer A to Buffer B starting at fraction 13. For further experimental details, see the text. $\bullet$, absorbance at $280 \mathrm{~nm} ; O$, distribution of radioactivity.

Fig. 2. Elution profile obtained after chromatography on CM-Sepharose CL-6B of 50 $\mathrm{mg}$ of an identical sample as used in Fig. 1. Here, the column was equilibrated with Buffer $C$ and the adsorbed globin chains eluted with a linear gradient of Buffer $C$ to Buffer D starting at fraction 18. For further experimental details, see the text. 1, $\alpha$ chains with hydroxyethyl adducts to the $N$-terminal valine; $2, \alpha$ chains with hydroxyethyl adducts to histidine- $N^{r}$. The insert shows the distribution of $N$-(2-hydroxyethyl)valine determined in the form of its PFPTH derivative.

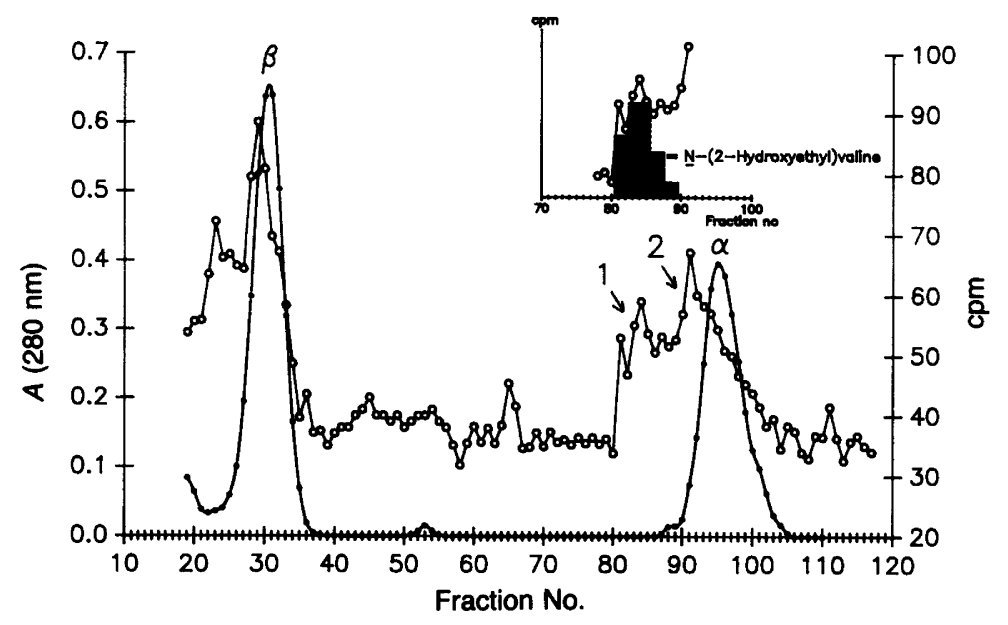

Fig. 2 shows the same globin sample chromatographed at $\mathrm{pH}$ 7.2. A separation of part of the radioactivity from the non-alkylated globin chains was obtained. The first radioactivity peak eluting just before the $\alpha$ chain contains adducts to $N$-terminal valine as found by radioactivity determination of the PFPTH derivatives. The second radio- activity peak, which also elutes just before the $\alpha$ chain, contains $N^{\tau}$-(2-hydroxyethyl)histidine. Chains containing $N^{\pi}$-(2-hydroxyethyl)histidine co-elute with the main $\alpha$ chain. ${ }^{23}$

Fig. 3 shows the $\left[{ }^{3} \mathrm{H}\right]$ styrene oxide-alkylated globin chromatographed at $\mathrm{pH}$ 7.2. Chains with adducts to $N$-terminal

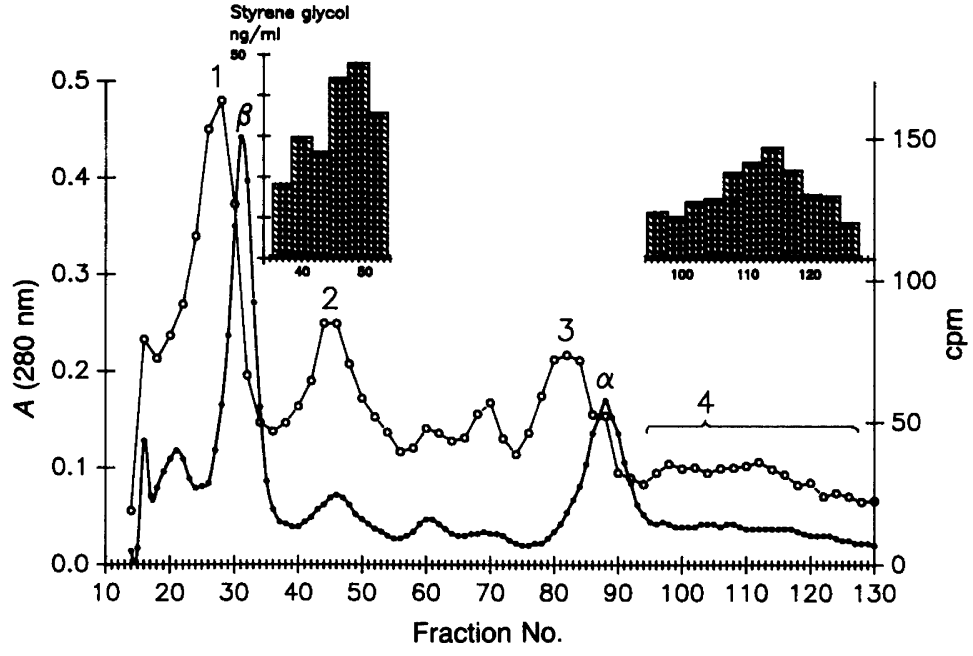

Fig. 3. Chromatography of globin chains alkylated in vitro with $\left[{ }^{3} \mathrm{H}\right]$ styrene oxide under conditions identical with those used in Fig. 2. The gradient starts at fraction 2. Peaks 2 and 4 contain chains with esterified carboxy groups. Peaks 1 and 3 contain chains with adducts to $N$-terminal valine. The insert shows the amount of 1-phenyl-1,2ethanediol (styrene glycol) released from the protein after mild acid hydrolysis. 


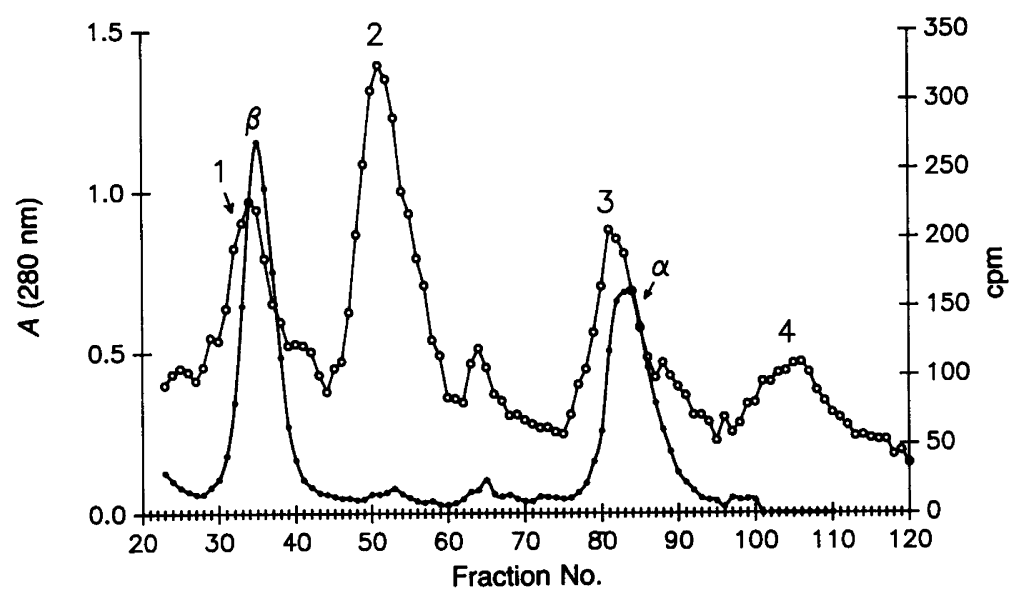

Fig. 4. Chromatography of globin chains alkylated in vitro with $\mathrm{N}-\left[{ }^{14} \mathrm{C}\right]$ ethyl- $\mathrm{N}$-nitrosourea under conditions identical with those used in Fig. 2. The gradient starts at fraction 2 . The peaks correspond to: $1, \beta$ chains with ethyl adducts to histidine, serine, threonine, cysteine and valine; 2 , $\beta$ chains with ethyl adducts to carboxy groups; 3 , $\alpha$ chains with ethyl adducts to histidine, serine, threonine, cysteine and valine; $4, \alpha$ chains with ethyl adducts to carboxy groups.

Fig. 5. lon-exchange separation on Dowex $50 \mathrm{Wx} 4$ of amino acids in a hydrolysate of the $\alpha$ chain (peak 3, Fig. 4) from $N-\left[{ }^{14} \mathrm{C}\right]$ ethyl- $\mathrm{N}$ nitrosourea-alkylated human globin. The positions of the following amino acids are indicated: 1 , O-ethylserine; 2 , O-ethylthreonine; 3 , ethylvaline; 4, S-ethylcysteine; $5, N^{\pi_{-}}$ ethylhistidine; $6, N^{\top}$-ethylhistidine.

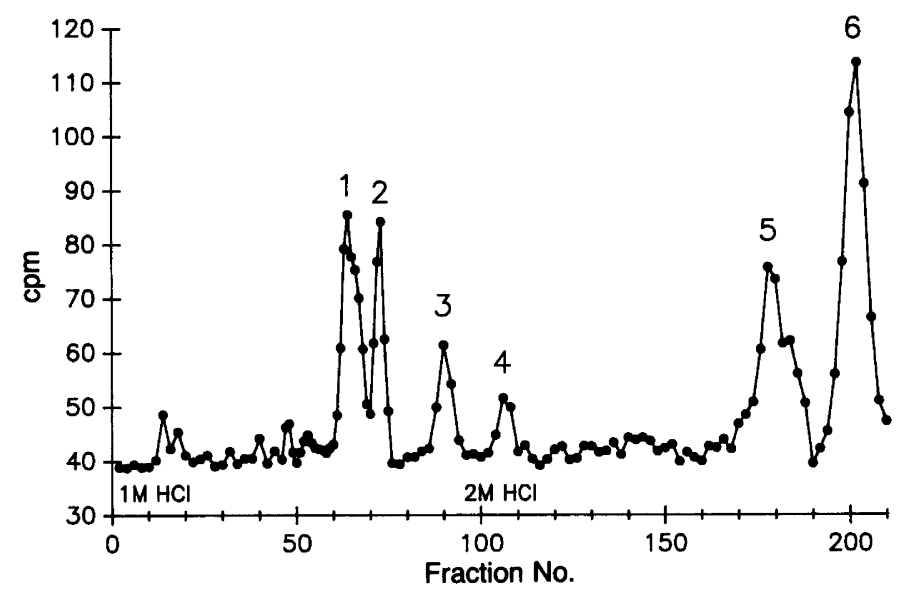

valine eluted before the non-alkylated chains as demonstrated by analysis of the PFPTH derivatives. The radioactivity peaks eluting after the non-alkylated chains (peaks 2 and 4) contain esterified carboxylic acid residues as shown by analysis of 1-phenyl-1,2-ethanediol. (The analyt- ical procedure for 1-phenyl-1,2-ethanediol is under development, and has so far given a background of unknown origin in biological samples.)

The results obtained after chromatography of $\mathrm{N}$ $\left[{ }^{14} \mathrm{C}\right]$ ethyl- $N$-nitrosourea-alkylated globin chains at $\mathrm{pH} 7.2$

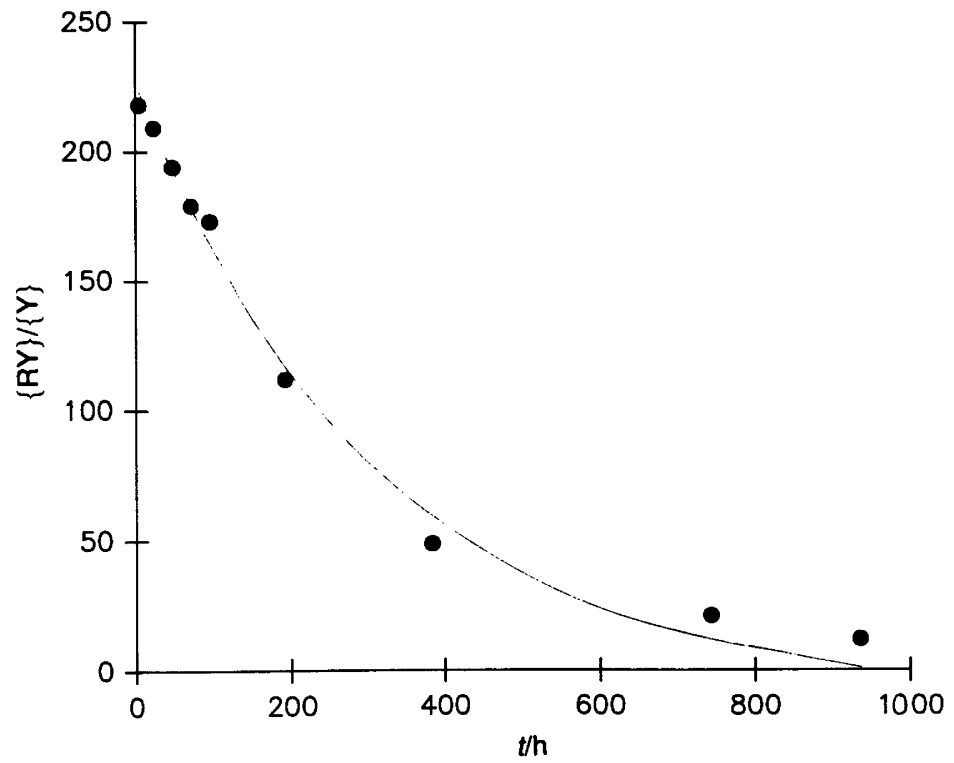

Fig. 6. Ethyl esters in mouse globin at different times after a single injection of $\mathrm{N}-\left[{ }^{14} \mathrm{C}\right]$ ethyl- $\mathrm{N}$ nitrosourea. The $y$-axis gives the amount of radioactivity recovered as ethanol by mild hydrolysis of the protein (cpm/mg globin). The disappearance of the adducts follows equation (1) where $\left([\mathrm{RY} /[\mathrm{Y}])^{\circ}( \pm \mathrm{SE})\right.$ has been estimated to $226.7( \pm 5.41)$ and $k( \pm S E)$ to $2.3( \pm 0.3) \times 10^{-3}$ $\mathrm{h}^{-1}$. 
are shown in Fig. 4. The radioactivity peaks eluting with the main $\alpha$ and $\beta$ chains (peaks 1 and 3 , respectively) were hydrolysed and the hydrolysate was chromatographed on Dowex $50 \mathrm{Wx} 4$ (Fig. 5). Peak 4 co-eluted with the added carrier $S$-ethylcysteine. The peaks 1,2 and 3 were assumed to be $O$-ethylserine, $O$-ethylthreonine and $N$-ethylvaline by comparison at the data with Osterman-Golkar and Bergmark. ${ }^{22}$ Peaks 5 and 6 were assumed to be $N^{\pi}$-ethyl- and $N^{\tau}$-ethyl-histidine, based on data presented by Murphy et al. ${ }^{17} N^{\tau}$-Ethylhistidine was also identified by re-chromatography of peak 6 (Fig. 4) together with the carrier.

The radioactivity peaks eluting after the parent $\beta$ and $\alpha$ chains (peaks 2 and 4, respectively, in Fig. 4) contain chains with esterified carboxylic acid residues. The degree of enrichment expressed as the ratio (protein in the parent chains)/(protein in the fractions of interest) was 15 and 28 for the ethyl esters in the $\beta$ and $\alpha$ chain, respectively.

The ethyl adducts to carboxylic groups are not entirely stable in vivo as shown by the experiment with mice (Fig. 6). The adduct disappears faster than the elimination of the erythrocytes, due to enzymatic or non-enzymatic hydrolysis. The disappearance follows theoretically eqn.

$$
\frac{[\mathrm{RY}]}{[\mathrm{Y}]}=\frac{[\mathrm{RY}]^{0}}{[\mathrm{Y}]} \times\left(1-\frac{t}{t_{\mathrm{er}}}\right) \exp (-k t)
$$

(1), where $[\mathrm{RY}] /[\mathrm{Y}]$ is the degree of alkylation at time $t$, $([\mathrm{RY}] /[\mathrm{Y}])^{\circ}$ the initial degree of alkylation, $k$ is the rate constant for the disappearance due to hydrolysis and $t_{\mathrm{er}}$ is the lifetime of the erythrocytes which is $\mathbf{4 0}$ days in the mouse. ${ }^{24}$ The rate constant, $k$, for the hydrolysis of the ethyl esters has been estimated from this experiment to be $2.3( \pm 0.3) \times 10^{-3} \mathrm{~h}^{-1}$. The disppearance of a stable adduct would follow the elimination of the erythrocytes, i.e. $1.04 \times 10^{-3} \mathrm{~h}^{-1}$.

\section{Discussion and conclusions}

Hemoglobin is composed of two identical $\alpha$-chains (each containing 141 amino acid residues) and two identical $\beta$ chains (each containing 146 amino acid residues). To each of these 4 chains is bound a heme group in a non-covalent, but stable, linkage. According to Righetti, ${ }^{25}$ the isoelectric points ( $\mathrm{p} I$ ) of $\alpha$ - and $\beta$-chains of human hemoglobin, determined in the presence of $8 \mathrm{M}$ urea, are estimated to be 7.8 and 7.1, respectively. This difference in total surface charge is effectively exploited for the baseline separation of these two globin chains at either pH 6.7 or 7.2 on a cation exchanger under the column equilibration and elution conditions which we have optimized for this purpose. As would be expected, the $\alpha$-chain $(\mathrm{p} I=7.8)$ is more firmly bound to the ion-exchanger and therefore elutes much later in the gradient than the $\beta$-chain. Increasing the $\mathrm{pH}$ of the equilibration buffer from 6.7 to 7.2 decreases the strength of binding of both chains to the cation exchanger. Despite this a much better separation of the alkylated chains is obtained at the higher $\mathrm{pH}$ as is evident from the series of results we have presented.

Chains containing an alkylvaline or alkylhistidine are separable from the main chains as a function of the change of $\mathrm{p} K_{\mathrm{a}}$ of the alkylated amino groups. The electron-withdrawing character of the 2-hydroxyethyl group leads to a lower $\mathrm{p} K_{\mathrm{a}}$, thus a lowering of the charge of the chain, and the appearance of the adducted fraction before the main chain. The $\mathrm{p} K_{\mathrm{a}}$ of $\mathrm{N}$-(2-hydroxyethyl)amine and $\mathrm{N}, \mathrm{N}$-di(2hydroxyethyl)amine are 9.50 and 8.88 , respectively. ${ }^{26}$ On this basis the 2-hydroxyethyl group on valine- $\mathrm{NH}_{2}$ is expected to lower the $\mathrm{p} K_{\mathrm{a}}$ analogously. The $\mathrm{p} K_{\mathrm{a}}$ values of $N^{\pi}$-(2-hydroxyethyl)histidine, $N^{\pi}$-(2-hydroxyethyl)histidine and histidine are 5.45, 6.1 and 6.1 , respectively, ${ }^{27}$ which explains the observed elution pattern of the adducted chains. The hydroxyphenethyl group is expected to have a similar impact on the $\mathrm{p} K_{\mathrm{a}}$ values.

The ethyl group has an electron-donating character. Chains with ethyl groups on cysteine, serine and threonine are expected to co-elute with the main chains. Chains ethylated on valine- $\mathrm{NH}_{2}$ are expected to elute soon after the parent chains ( $N$-ethylamine and $N, N$-diethylamine have $\mathrm{p} K_{\mathrm{a}}=10.7$ and 11.0, respectively; see Ref. 26). Chains ethylated in the $N^{\tau}$-position of histidine residues would elute just before the parent chains and the chains ethylated in the $N^{\pi}$-position of histidine just after. Methylation at the $N^{\tau}$-position of the histidine residue in the tripeptide thyrotrophin-releasing factor lowers the $\mathrm{p} K_{\mathrm{a}}$ to $5.95 .{ }^{28}$ The $\mathrm{p} K_{\mathrm{a}}$ values of the parent compound and of the $N^{\pi}$-methylated isomer values are 6.25 and 6.6 , respectively.

Alkylation at carboxy- $O$ changes the charge by +1 . The chains are retarded and thus elute in fractions well separated from the main chains, as shown for globin alkylated with $N$-ethyl- $N$-nitrosourea or styrene oxide. The method is therefore especially suitable for enrichment of globin chains with non-charged adducts to carboxylic groups. The adducts can then be hydrolysed from the enriched fraction, and a sample with several adducts in the form of alcohols can be obtained. Such a sample could then be suitable for identification of adducts from unknown exposure sources.

The degree of enrichment of globin chains with an esterified carboxy group is limited by the presence of chains where, due to errors during de novo synthesis, substitution of an amino acid has led to an increase in charge (e.g. substitution of an acidic amino acid for a neutral one). The error frequency in protein synthesis has been estimated as about 3 parts per 10,000 with respect to substitution of valine for leucine ${ }^{29}$ and similar values have been estimated for substitution of cysteine for arginine or tryptophan (cf. Refs. 30 and 31). The competition ratios for amino acids not normally present in cells may be orders of magnitude higher (cf. Ref. 32). The separation technique described here might well be suited as a method for studying misincorporation during hemoglobin synthesis.

The present study shows that ethyl esters in hemoglobin are hydrolysed at a rate which is not negligible compared with the rate of elimination of the erythrocytes, but that 
they are stable enough to be useful for dose monitoring. The stability of different esters will be determined by the structure of the adduct introduced and has to be studied in each case. Current studies at this laboratory concern the in vivo stability of hemoglobin adducts of styrene oxide.

This study will be extended to investigate the increase in analytical sensitivity and the practical use of enriched alkylated globin chains for hemoglobin dosimetry. The procedure has already been successfully applied to the quantification of adducts to $N$-terminal valine in styrene-exposed workers. $^{33}$

Acknowledgements. We thank Professor L. Ehrenberg, Dr. G.-P. Scalia-Tomba and Dr. C. J. Calleman for valuable discussions and Fredrik Granath for mathematical treatment of data. Thanks are also due to Mr Vlado Zorcec for skilful technical assistance. The work was supported financially by the Swedish Cancer Society, the National Swedish Environment Protection Board, Shell Internationale Research Maatschappij B. V., an Ecetoc task force and the Swedish Natural Research Council (M.B.).

\section{References}

1. Miller, E. C. and Miller, J. A. Pharmacol. Rev. 18 (1966) 805.

2. Osterman-Golkar, S., Ehrenberg, L., Segerbäck, S. and Hällström, I. Mutat. Res. 34 (1976) 1.

3. Ehrenberg, L. and Osterman-Golkar, S. Teratog. Carcinog. Mutag. 1 (1980) 105.

4. Neumann, H.-G. In: Hayes, A. W., Schnell, R. C. and Miya, T.S. Eds., Developments in the Science and Practice of Toxicology, Elsevier, Amsterdam 1983, p. 135.

5. Ehrenberg, L. Radiobiological Equivalents of Chemical Pollutants. IAEA, Vienna 1980 , p. 23 , see also p. 11.

6. Ehrenberg, L., Moustacchi, E. and Osterman-Golkar, S. Mutat. Res. 123 (1983) 121.

7. Calleman, C. J., Ehrenberg, L., Jansson, B., Osterman-Golkar, S., Segerbäck, D., Svensson, K. and Wachtmeister, C. A. J. Environ. Pathol. Toxicol. 2 (1978) 427.

8. Farmer, P. B., Bailey, E., Gorf, S. M., Törnqvist, M., Osterman-Golkar, S., Kautiainen, A. and Lewis-Enricht, D. P. Carcinogenesis 7 (1986) 637.

9. Osterman-Golkar, S., Bailey, E., Farmer, P. B., Gorf, S. M. and Lamb, J. H. Scand. J. Work. Environ. Health 10 (1984) 99.

10. Törnqvist, M., Osterman-Golkar, S., Kautiainen, A., Jensen, S., Farmer, P. B. and Ehrenberg, L. Carcinogenesis 7 (1986) 1519.

11. Stevens, V. J., Fantl, W. J., Newman, C. B., Sims, R. V., Cerani, A. and Peterson, C. M. J. Clin. Invest. 67 (1981).

12. Clegg, J. B., Naughton, M. A. and Weatherall, D. J. J. Mol. Biol. 19 (1966) 91.

13. Ehrenberg, L. and Hussain, S. Mutat. Res. 86 (1981) 1.

14. Velemínský, J., Osterman-Golkar, S. and Ehrenberg, L. Mutat. Res. 10 (1970) 169.

15. Osterman-Golkar, S. To be published.

16. Duverger-van Bogaert, M., Noel, G., Rollman, B., Cumps, J., Roberfroid, M. and Mercier, M. Biochim. Biophys. Acta 526 (1978) 77.

17. Murthy, M. S. S., Calleman, C. J., Osterman-Golkar, S., Segerbäck, D. and Svensson, K. Mutat. Res. 127 (1984) 1.

18. Segerbäck, D., Calleman, C. J., Ehrenberg, L., Löfroth, G. and Osterman-Golkar, S. Mutat. Res. 49 (1978) 71.

19. Mowrer, J., Törnqvist, M., Jensen, S. and Ehrenberg, L. Toxicol. Environ. Chem. 11 (1986) 215.

20. Lowry, O.H., Rosebrough, N. J., Farr, A.L. and Randall, R. J. J. Biol. Chem. 193 (1951) 265.

21. Törnqvist, M., Kautiainen, A., Gatz, R. N. and Ehrenberg, L. J. Appl. Toxicol. 8 (1988) 159.

22. Osterman-Golkar, S. and Bergmark, E. Carcinogenesis 9 (1988) 1915

23. Calleman, C. J. Unpublished data.

24. von Ehrenstein, G. Acta Physiol. Scand. 44 (1958) 80.

25. Righetti, P. G., Gianazzi, E., Gianni, A. M., Comi, P., Giglioni, B., Ottolenghi, S., Secchi, C. and Rossi-Bernardi, L. J. Biochem. Biophys. Meth. 1 (1979) 45.

26. Perrin, D. D. Dissociation Constants of Organic Bases in Aqueous Solution, Butterworths, London 1965.

27. Calleman, C. J. and Wachtmeister, C. A. Acta Chem. Scand., Ser. B 33 (1979) 277.

28. Grant, G., Ling, N., Rivier, J. and Vale, W. Biochemistry 11 (1972) 3070

29. Loftfield, R. B. and Vanderjagt, D. Biochem. J. 129 (1972) 1353.

30. Edelman, P. and Galland, J. Cell 10 (1977) 131.

31. Bouadloun, R., Donner, D. and Kurland, C. G. EMBO J 2 (1983) 1351.

32. Loftfield. Res. Mol. Biol. 12 (1972) 87.

33. Christakopoulos, A., Svensson, K., Bergmark, E. and Osterman-Golkar, S. Carcinogenesis. Submitted.

Received November 24, 1989. 